\title{
The Effect of Organism Density on Bioaccumulation of Contaminants from Sediment in Three Aquatic Test Species: A Case for Standardizing to Sediment Organic Carbon
}

\author{
J. L. Van Geest • D. G. Poirier · K. R. Solomon • \\ P. K. Sibley
}

Received: 13 March 2010/Accepted: 28 June 2010/Published online: 17 July 2010

(C) Springer Science+Business Media, LLC 2010

\begin{abstract}
Laboratory methods for measuring bioaccumulation of organic contaminants from sediment into aquatic organisms continue to improve, but some aspects are still in need of standardization. From a review of published methods, we noted that the loading density of organisms was determined inconsistently and was primarily based on either sediment volume or total organic carbon (TOC). The rationale mainly expressed for standardizing to TOC was to minimize the depletion of sediment contaminants. However, even when density was standardized to TOC, the relative amount of TOC provided (i.e., ratio of TOC to organism dry weight $[\mathrm{dw}]$ ) was highly variable. In this study, we examined the effect of organism density (standardized to sediment TOC or volume) on bioaccumulation in three freshwater organisms. The oligochaete Lumbriculus variegatus, mayfly nymph Hexagenia spp., and fathead minnow Pimephales promelas were exposed for 28 days to two field-contaminated sediments that varied in concentration of PCBs and TOC. Densities tested were 50:1 and 27:1 ratios of TOC to organism $\mathrm{dw}$ and $140 \mathrm{ml}$ sediment/g wet weight (ww) biomass, yielding low to high organism densities. Bioaccumulation in Hexagenia spp. was significantly higher at the lowest organism density
\end{abstract}

Electronic supplementary material The online version of this article (doi:10.1007/s00244-010-9573-7) contains supplementary material, which is available to authorized users.

J. L. Van Geest $(\bowtie) \cdot$ K. R. Solomon · P. K. Sibley

School of Environmental Sciences, University of Guelph,

Guelph, ON N1G 2W1, Canada

e-mail: jvangees@uoguelph.ca

D. G. Poirier

Laboratory Services Branch, Ontario Ministry

of the Environment, 125 Resources Rd, Etobicoke,

ON M9P 3V6, Canada compared with the highest organism density when exposed to site 2 sediment ( $1.1 \%$ TOC) but only with tissue concentrations expressed on a ww basis. Otherwise, there was no significant effect of density on bioaccumulation in organisms exposed to sediments from site 1 (12\% TOC) or site 2. Survival of Hexagenia spp. was adversely affected at the highest organism density when the relative amount of TOC was low. The results of this study support the recommendation of standardizing organism density relative to a particular amount of TOC for invertebrate species. A 27:1 ratio of TOC:organism dw was selected as a standard organism density for a new bioaccumulation method because survival, growth, and bioaccumulation were not impacted relative to a 50:1 ratio, and less sediment was required. This density is recommended as an appropriate ratio for sediment bioaccumulation assessments in general.

Sediment serves as both a habitat and a food source for many benthic species, but it also represents an important route of exposure to environmental contaminants. An assessment of the potential for the biomagnification of contaminants is one of the four lines of evidence currently used in decisionmaking frameworks for the assessment of sediments (Chapman and Anderson 2005; Grapentine et al. 2002). Laboratory methods to assess the toxicity (i.e., impact on growth, survival, and reproduction) of sediments have been standardized (e.g., Environment Canada 1997a, b; United States Environmental Protection Agency [USEPA] 2000). However, methods for measuring the bioaccumulation of contaminants from sediment into aquatic organisms are often applied using inconsistent test parameters and as such have not achieved the same level of standardization.

We reviewed published methods for research-based and applied bioaccumulation testing with sediment to identify 
and evaluate the frequency of use of various exposure techniques, test organisms, and conditions as well as to identify data gaps within these protocols (see Van Geest et al. 2010 for a critical review of methods). One of the most noted inconsistencies between bioaccumulation methods was the loading density of organisms. Many of the studies reviewed based the density of organisms on sediment volume, whereas in others TOC content of sediment was used. Some researchers recommended providing a particular ratio of TOC in sediment to organism dry weight (dw) to minimize the depletion of contaminants throughout the test (American Society for Testing and Materials [ASTM] American Society for Testing and Materials 2000; USEPA 2000; You et al. 2007). However, even with the commonly used oligochaete $L$. variegatus, ratios of TOC to organism dw ranged from 10:1 to 100:1 (e.g., Harkey et al. 1995; Kukkonen and Landrum 1994, 1995). Kukkonen and Landrum (1994) unexpectedly observed that the bioaccumulation of pyrene by $L$. variegatus increased with increasing density of worms, suggesting that the worms were not depleting the available contaminant in 14-day tests. Lyytikäinen et al. (2007) transplanted L. variegatus into fresh sediment at regular intervals during 12 days to investigate the depletion of the rapidly desorbing (labile) fraction of Polycyclic aromatic hydrocarbons (PAHs) from sediment and porewater and found that this had a minor effect on bioaccumulation in this species. In contrast, Lotufo et al. (2000) observed greater bioaccumulation in the marine polychaete Neanthes arenaceodentata when organisms were exposed to sediment individually compared with groups of five. These results suggest that additional testing of the loading density of test organisms is warranted to determine its affect on bioaccumulation to standardize this component in bioaccumulation methods.

It has been suggested that the amount of sediment provided in a bioaccumulation test should exceed by 2 - to 5-fold the total amount of sediment processed during the test duration (ASTM 2000). However, this requires knowledge of the processing rates of particular species, which can vary with sediment grain size and content of organic carbon (Leppänen 1995; Leppänen and Kukkonen 1998). From their study of organism density, Kukkonen and Landrum (1994) suggested that a standard organism density relative to sediment organic carbon should be established to ensure that exposures are similar among tests. They commented that an optimal loading density is uncertain because the mechanism of differential accumulation is unknown, but they suggested that a 50:1 ratio of TOC:organism $\mathrm{dw}$ is appropriate. However, no rationale was given for the recommendation of this particular ratio, and bioaccumulation was not highest at this loading density. The ASTM (2000) and the USEPA (2000) bioaccumulation methods with $L$. variegatus recommend using this
50:1 ratio to ensure the availability of sufficient food and to minimize the depletion of contaminants. This is likely based on the recommendations of Kukkonen and Landrum (1994), but again no rationale is provided for its selection, and there is no experimental evidence to indicate the appropriateness of this ratio in 28-day sediment exposures.

The objective of the present study was to examine the effect of organism density (total biomass of individuals standardized to sediment volume or TOC) on the bioaccumulation of Polychlorinated biphenyls (PCBs) from field-contaminated sediment into three freshwater organisms. Due to the inconsistent way in which loading density is determined (sediment volume or TOC), we wanted to investigate the impacts and variability associated with each approach. In addition, we tested different ratios of TOC:organism $d w$ to assess whether a ratio $<50: 1$ is sufficient because this can provide practical benefits (i.e., less sediment to collect and process and from which to recover organisms at the end of a test). Our goal was not to determine an optimal loading density per se but rather to identify one that does not inhibit bioaccumulation by providing sufficient carbon and food to prevent significant weight loss and starvation metabolism in the test organisms while minimizing the amount of sediment used.

Apart from the studies by Kukkonen and Landrum (1994) and Lotufo et al. (2000), we are not aware of any other studies that have investigated whether and how bioaccumulation in test species is affected by the density of organisms. The present study is different from the other two studies in that it examines a much narrower range of organism densities (approximately 1.5 to $3.5 \times$ difference between treatments vs. 2 to $10 \times$ in Kukkonen and Landrum (1994) and $5 \times$ in Lotufo et al. (2000)). Bioaccumulation tests in these other studies were conducted with spiked sediment and the use of radiolabeled compounds and were able to use relatively few and small organisms. Therefore, the tests were not restricted by very low loading densities (or high ratios of TOC:organism dw), which would otherwise require large volumes of sediment from which to recover organisms due to sample requirements (1 to $5 \mathrm{~g}$ ww tissue) of the analytical methods used for environmental samples. Compared with those studies, the present study also examined the effect of density on three different species (L. variegatus, Hexagenia spp., and P. promelas) under standard conditions. This includes the mayfly nymph Hexagenia spp. (for which the impact of organism density and proportion of sediment TOC in a test has not been previously investigated) and the juvenile fathead minnow $P$. promelas (for which there is only one published method for sediment testing (i.e., Bedard et al. 1992)). Standardizing loading density between the sediments tested is not only important for a particular species, but using a common approach for multiple species will allow for more accurate 
comparisons of bioaccumulation between species because loading is independent of organism size. The research presented in this article is part of a larger project aimed at developing and standardizing bioaccumulation procedures with sediment for the Ontario Ministry of the Environment (OMOE; e.g., Van Geest et al. 2010).

\section{Materials and Methods}

\section{Test Organisms}

The oligochaete worm $L$. variegatus, mayfly nymph Hexagenia spp., and fathead minnow $P$. promelas were chosen for the development of bioaccumulation methods to represent different taxa, trophic levels, and bioaccumulation potential (e.g., routes of exposure, metabolic capabilities). Although fathead minnows do not interact with the sediment to the same extent as L. variegatus and Hexagenia spp. (which burrow into and ingest sediment), they often resuspend sediment due to their (feeding) behaviour and were included in this study as part of the method development. Oligochaetes and fish were raised from OMOE in-house cultures according to standard operating procedures (based on Bedard et al. 1992; USEPA 1987, 2000). Mayflies are difficult to continuously culture, so eggs were collected in the field from emerged adults (by J. Ciborowski, University of Windsor), stored, then hatched and reared in the laboratory (based on Bedard et al. 1992; Hanes et al. 1990). All water used in culturing and testing was dechlorinated tap water from the city of Toronto.

\section{Sediment}

Control and PCB-contaminated sediments were collected from different locations in southwestern Ontario. Before use in any experiments, all control and test sediments were homogenized and subsampled for full physicochemical characterization (particle size, moisture, TOC, bulk density, nutrients, metals, and organic contaminants). All samples were stored at approximately $4^{\circ} \mathrm{C}$ in the dark before and between laboratory exposures. Two contaminated sediments were selected for this experiment because they differed in concentration of PCBs and physical parameters, such as total organic carbon (Table S1).

\section{Bioaccumulation Tests}

Organisms were exposed to the control and two PCBcontaminated sediments at three different loading densities. The densities used in this experiment were 50:1 and 27:1 ratios, respectively, of TOC:organism dw (based on
Leppänen and Kukkonen 2004; USEPA 2000) and $140 \mathrm{ml}$ sediment/g wet weight ( $\mathrm{ww}$ ) biomass (designated as a standard volume treatment). This latter density was derived from the minimum tissue requirements of analytical procedures and the commonly used ratio of sediment to overlying water ratio (1:4) while working within the confines of appropriate test vessels (i.e., 2- or 4-1 glass jars). Although this loading density was not based on an existing test methodology, it was chosen to represent an organism density that was high but that could potentially support the survival of organisms for 28 days. With the sediments chosen for this experiment, this standard volume treatment resulted in a range of ratios of TOC to organism dw, which typically were low (Table S2).

The volume of sediment required for each treatment was calculated based on $5 \mathrm{~g}$ ww biomass required for chemical analysis using sediment- and organism-specific parameters (Tables S1, S2). Control sediment A was used with Hexagenia spp. and $P$. promelas, and control sediment B was used with $L$. variegatus due to sediment differences (i.e., particle size distribution and density; Table S1) that had affected performance of the invertebrate species in earlier sediment tests (OMOE; Van Geest [unpublished data]). Sediment and water were added to 4-L glass jars in a ratio of 1:4 (v/v; Bedard et al. 1992) 1 day before test initiation. Due to differences in TOC, moisture content, and density of sediment, large volumes of sediment were required for certain treatments. If the total volume of sediment and overlying water calculated for a treatment exceeded the capacity of the jar, then sediment, water, and organisms were equally split between jars to maintain the same loading density and the 1:4 sediment-to-water ratio. Organisms from the split treatments were then pooled at the end of the test. Each vessel was loosely fitted with a lid with a hole through which the overlying water was aerated with filtered air supplied by way of a Pasteur pipette.

The test sediments were screened for toxicity using a 4-day acute toxicity test to ensure survival of organisms during the 28-day exposure period (survival was $\geq 80 \%$ ). At initiation of the bioaccumulation test, approximately the same number of organisms (only nymphs and fish were enumerated), weighing approximately $5 \mathrm{~g}$ total ww/replicate, were added to each test container. Approximately 1.3 times the required amount of worm tissue was added to account for excess water (USEPA 2000). A sample of organisms for each species was collected for pre-exposure analysis. The average ww of mayfly nymphs was 20 to $30 \mathrm{mg}$ and for fish was 250 to $500 \mathrm{mg}$.

Organisms were exposed to sediment for 28 days under static conditions with aeration of overlying water (static exposure based on Bedard et al. 1992; Environment Canada 1997a, b). Tests were conducted at $23 \pm 2^{\circ} \mathrm{C}$ 
under a $16 \mathrm{~h}: 8 \mathrm{~h}$ light-to-dark photoperiod of 500-1000 lux. Fish were fed a maintenance diet of ground Nutrafin fish food flakes at a rate of approximately $1 \%$ wet body weight/d (Bedard et al. 1992). No food was added to the exposures containing worms or nymphs.

At termination of the test, overlying water from each treatment was collected (and pooled for split treatments) for chemical analyses. Organisms were sieved from the sediment $(243-\mu \mathrm{m}$ and $1-\mathrm{mm}$ mesh size for worms and nymphs, respectively), rinsed, killed in $\mathrm{CO}_{2}$-charged water (accepted method per personal communication from $\mathrm{W}$. Holley and D. McGrogan), weighed, and frozen. Survival was recorded for nymphs and fish. Water quality $(\mathrm{pH}$, conductivity, temperature, dissolved oxygen, and ammonia) was measured at the beginning and end of the tests using ion-specific meters according to OMOE standard operating procedures (data reported in Table S3). All preexposure, control, and test organisms were analyzed for PCBs and lipid content.

This study was designed with nine treatments used in each test ( 1 control, 2 test sediments $\times 3$ densities). Due to the large number of organisms required and the workload constraints of recovering organisms from large volumes of sediment, each test was conducted with only one replicate per treatment. Tests were then repeated three times during 3 months. Therefore, time potentially may have been a source of variation between tests. Tests for the three species were set up on different days, again due to workload constraints, but at any one time were offset by 1 or 2 days.

\section{Physicochemical Analyses}

Sediment density was determined by measuring $100-\mathrm{ml}$ aliquots of sediment into preweighed beakers $(n=5)$. Each sample was weighed before and after drying in an oven (at approximately $60^{\circ} \mathrm{C}$ for approximately 5 days). Wet-to-dry weight conversion factors for each species were also determined by weighing organisms $(n=20)$ before and after drying in an oven (at approximately $60^{\circ} \mathrm{C}$ for 24 to $48 \mathrm{~h}$ ). All other physical and chemical analyses of sediment and tissue samples were conducted by the OMOE Laboratory Services Branch according to their standard operating procedures (summarized later in text). All chemical analyses included the use of quality-control procedures, such as internal standards, laboratory blanks and spikes, duplicates, matrix spikes, and certified reference materials, as appropriate. All analytical methods (and the working instructions for measuring water quality) were externally audited (by the Standard Council of Canada and/ or Canadian Association of Laboratory Accreditation) and are accredited to ISO 17025-2005. The most relevant analytical procedures are briefly described later in the text.
TOC was determined by subtracting the total inorganic carbon from the amount of total carbon. Total carbon was measured by combustion using a LECO C-632 Carbon Determinator (OMOE 2008a). Inorganic carbon was determined by measurement of $\mathrm{CO}_{2}$ produced by the reaction of carbonate with $2 \mathrm{~N}$ perchloric acid using a coulometer (OMOE 2008b). The distribution of particle size in sediment samples was measured with a Coulter LS230 Particle Size Analyzer (OMOE 2008c).

For the measurement of congener-specific PCBs, sediment samples were air-dried; extracted twice with acetone and $25 \%(\mathrm{v} / \mathrm{v})$ dichloromethane in hexane using an ultrasonic bath; and then vortex shaken. Thawed tissue samples were acid-digested using concentrated hydrochloric acid, then extracted using $25 \%$ (v/v) dichloromethane in hexane. Lipid content was determined gravimetrically using an aliquot of the final extract from each tissue sample. An aliquot of each extract (sediment or tissue) was cleaned up using preconditioned Florisil before analysis by a gas-liquid chromatograph equipped with electron capture detectors (OMOE 2007, 2008d). Detection limits of individual PCB congeners ranged from 0.4 to $22 \mathrm{ng} / \mathrm{g}$ ww. Quality-control data collected during a 1-year period (2007-2008) for these methods showed a precision range of 4.6 to $15 \%$ for all congeners (except for two rare coplanar compounds) and recoveries from 74 to $98 \%$ on matrix-spiked samples (using certified reference materials).

\section{Data and Statistical Analyses}

All data reported are the sum of total PCB congeners measured in the method, with congener values lower than reporting limits treated as zero. The concentration of total PCBs in all pre-exposure and control organisms were detected at or lower than trace levels; therefore, no corrections were made to the 28-day concentrations measured in test organisms. Statistical comparisons between test species and between test sediments were outside the scope of this study but will be investigated in future work assessing bioaccumulation potential between species. Analysis of variance (ANOVA; with Tukey multiple comparison) was used for comparing mean survival, growth, or tissue concentrations between loading density treatments for each sediment and organism tested (mean of three tests). Tests for normality (Kolmogorov-Smirnov) and equal variance (Leven median) were incorporated into the ANOVA (SigmaStat v. 3.5). Lipid-normalized tissue concentrations for $L$. variegatus exposed to site 2 sediment were log-transformed to meet the assumption of normality. All other data sets met the assumptions of normality and equal variance. Differences were considered significant at $P<0.05$. 


\section{Results}

Survival, Growth, and Lipid Content

Survival and growth end points for L. variegatus are difficult to separate in bioaccumulation tests due to their asexual mode of reproduction and the large number of worms required to achieve sufficient biomass for chemical analyses. Therefore, total biomass (ww) was measured as an end point for this species. Total biomass of $L$. variegatus decreased (by $10 \%$ to $50 \%$ ) in all sediments and density treatments during the 28 days, with the exception that a approximately $10 \%$ increase in biomass was observed in the 50:1 treatment for site 1 sediment in two of the three tests. Although growth was slightly higher in this (50:1 site 1) treatment, there were no apparent trends in growth with respect to the ratio of TOC:organism dw for any of the

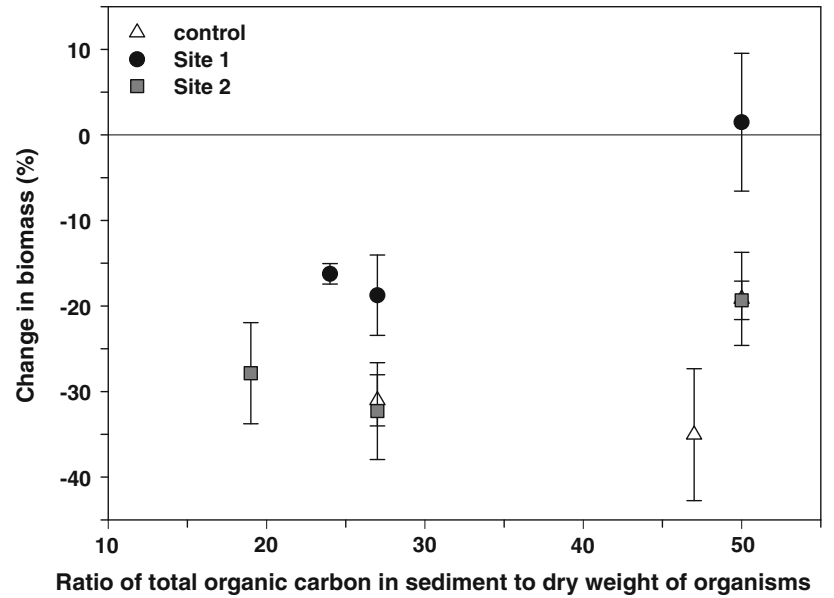

Fig. 1 Change in total biomass of $L$. variegatus at different ratios of TOC:organism dw after 28 days exposure to a control and two PCBcontaminated sediments. Data are reported as means and SEs generated from repeated tests $(n=3)$ sediments tested (Fig. 1). Within each sediment, there was no significant difference in mean growth (\% change in biomass) between density treatments. The lipid content of oligochaetes recovered at the end of the test did not appear to be affected by organism density because it was similar across density treatments within sediments within each test (data no shown). The only exception was that in test 3 with site 2 sediment, lipid content of organisms in the standard volume treatment was much lower $(0.2 \%)$ compared with the 27:1 and 50:1 treatments (0.6\% for both). This difference in lipid content was not associated with a greater loss in biomass, but because this treatment had the lowest ratio of TOC:organism dw (19:1) tested for L. variegatus, it could be that organism response is more variable when TOC is more limited.

Mean survival of Hexagenia nymphs was $\geq 89 \%$ in all treatments except in the standard volume treatment of the control and site 2 sediments (79 and 66\%, respectively). The acceptability criterion for survival of Hexagenia spp. in a 21-day toxicity test is $85 \%$ in Bedard et al. (1992) and $80 \%$ in the current version of the OMOE method (2008e). Nymph survival in the standard volume treatment was low in test 1 for the control (55\%) and in tests 1 and 3 for site 2 sediment (63 and 44\%). Survival was high in all other tests and treatments (Table 1). There was no significant difference in mean survival of nymphs between density treatments (within each sediment), but it appears that survival was more variable and likely to be impacted when there was a low ratio of TOC:organism dw (Fig. 2). Nymphs increased in biomass in almost all cases, with mean growth (\% increase in average ww) ranging from $15 \%$ to approximately $100 \%$ during the 28 days. A trend of increased growth with increased TOC content (=decreased organism density) was observed in each sediment (Fig. 2); however, there was only a significant difference in growth between the highest and lowest density in the control sediment. This
Table 1 Survival, growth, and lipid content of Hexagenia spp. exposed for 28 days to control and test sediments at three loading densities
Loading densities $=50: 1$ and 27:1 TOC:organism dw and $140 \mathrm{ml}$ sediment/g ww tissue. Bold text indicates impacted survival. Italic text indicates growth and lipid content that are relatively low

\begin{tabular}{|c|c|c|c|c|c|c|c|c|c|}
\hline \multirow[t]{2}{*}{ Site } & \multicolumn{3}{|c|}{ Survival (\%) } & \multicolumn{3}{|c|}{ Growth (\% change average ww) } & \multicolumn{3}{|c|}{ Lipid content $(\%)$} \\
\hline & Test 1 & Test 2 & Test 3 & Test 1 & Test 2 & Test 3 & Test 1 & Test 2 & Test 3 \\
\hline \multicolumn{10}{|l|}{ Control } \\
\hline $50: 1$ & 93 & 79 & 96 & 92 & 128 & 82 & 0.8 & 0.5 & 0.6 \\
\hline $27: 1$ & 100 & 99 & 95 & 57 & 62 & 23 & 0.6 & 0.4 & 0.4 \\
\hline $140 \mathrm{ml} / \mathrm{g}$ & 55 & 85 & 96 & 36 & 41 & 5 & 0.6 & 0.2 & 0.3 \\
\hline \multicolumn{10}{|l|}{ Site 1} \\
\hline $50: 1$ & 96 & 77 & 97 & 38 & 74 & 24 & 0.6 & 0.4 & 0.4 \\
\hline $27: 1$ & 97 & 98 & 93 & 15 & 45 & 5 & 0.4 & 0.5 & 0.9 \\
\hline $140 \mathrm{ml} / \mathrm{g}$ & 90 & 99 & 92 & 14 & 39 & -3 & 0.4 & 0.7 & 0.8 \\
\hline \multicolumn{10}{|l|}{ Site 2} \\
\hline $50: 1$ & 94 & 83 & 99 & 68 & 77 & 24 & 0.7 & 0.6 & 0.8 \\
\hline $27: 1$ & 100 & 100 & 93 & 18 & 26 & 6 & 0.6 & 0.5 & 0.7 \\
\hline $140 \mathrm{ml} / \mathrm{g}$ & 63 & 91 & 44 & 12 & 5 & 27 & 0.7 & 0.2 & 0.5 \\
\hline
\end{tabular}




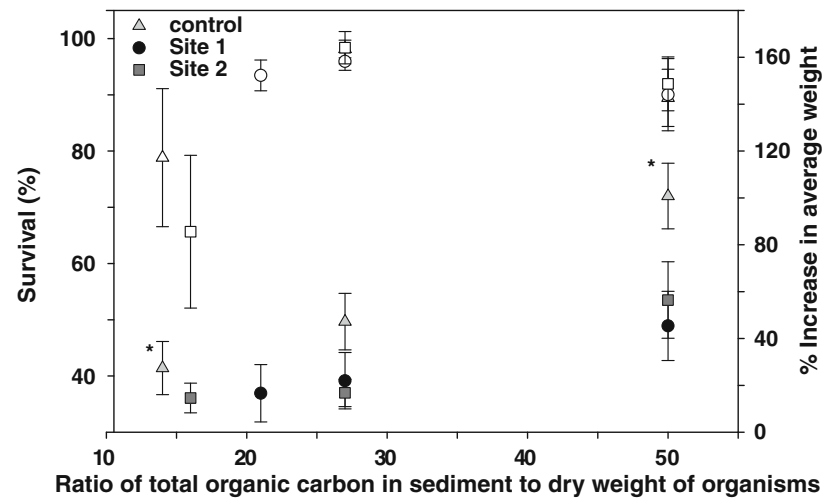

Fig. 2 Survival (open symbols) and growth (increase in average weight; closed symbols) of Hexagenia spp. at different ratios of TOC:organism dw after 28-day exposure to a control and two PCBcontaminated sediments. Data are reported as mean and SEs generated from repeated tests $(n=3$ tests). * Statistically significant results (ANOVA $P \leq 0.05$ )

lack of effect on growth is somewhat confounded by the fact that survival was sometimes impacted when the ratios of TOC:organism dw were low (i.e., $\leq 16: 1$ in control and site 2 sediment), thereby decreasing organism density allowing for relatively greater growth of the surviving nymphs, compared with when survival was not impacted (Table 1). Lipid content of Hexagenia spp. did not appear to be affected by the differences in organism density between the 50:1 and 27:1 treatments. However, when the ratio of TOC:organism $\mathrm{dw}$ was low in the standard volume treatment, lipid content of organisms was lower than in the other two density treatments only when survival was not impacted (Table 1). As with growth (change in average ww), this is due to competition for the limited TOC resources and when mortality occurs, thus decreasing competition (i.e., test 1 for control and tests 1 and 3 for site 2), organisms are able to maintain a typical lipid content.

Mean survival of $P$. promelas was $\geq 94 \%$ in all treatments and mean growth (\% increase in average ww) ranged from 6 to 28\%, which was acceptable organisms performance. Within each sediment, growth was slightly lower and more variable when ratios of TOC:organism dw were low. However, there was no significant difference in survival or growth between density treatments within each sediment. Lipid content of fish was not affected by organism density (data not shown).

\section{Bioaccumulation}

Due to the partitioning of many organic contaminants into the lipid of organisms, it is common practice to normalize tissue concentrations for lipid content to decrease variability. Because tests were repeated over time in the present study, lipid-normalization should account for differences in lipid content of organisms between tests and indicate whether bioaccumulation was consistent over time. Lipid-normalization should also account for bioaccumulation differences between density treatments that were related to differences in lipid content of organisms because differential growth sometimes occurred between treatments. However, there is also the potential for greater uncertainty associated with very low measurements of lipid content, and there are situations where lipid-normalization can greatly increase variability in the estimate of tissue concentration. Therefore, data related to ww concentrations are also presented to demonstrate these differences.

In the present study, tests were repeated over time, so there is the potential for temporal variability associated with the estimate of bioaccumulation of PCBs. To assess this, coefficients of variation $(\mathrm{CVs})$ were calculated for both ww and lipid-normalized tissue concentrations for each treatment (density-sediment-species). In almost all cases, the CVs for ww concentrations were $\leq 30 \%$ and similar to the within-test variability observed for total PCBs with each species (Table 2; based on later testing of various sediments with a 27:1 density and 3 replicates/test; Van Geest [unpublished data]). This suggests that biological variability was a greater source of uncertainty than any temporal variability that may have been associated with the present study. The CVs for lipid-normalized data were also in a similar range as the within-test variability, with one major exception (i.e., L. variegatus; site $2140 \mathrm{mg} / \mathrm{g}$ ). These CVs were sometimes higher than those for ww concentrations and may be influenced by differences in lipid content that were test- and density-specific.

Table $2 \mathrm{CVs}(\%)$ of ww and lipid-normalized tissue concentrations of PCBs in test species exposed to sediment for 28 days at three loading densities

\begin{tabular}{|c|c|c|c|c|c|c|}
\hline \multirow[t]{2}{*}{ Site } & \multicolumn{2}{|c|}{ L. variegatus } & \multicolumn{2}{|c|}{ Hexagenia spp. } & \multicolumn{2}{|c|}{ P. promelas } \\
\hline & ww & Lipid & ww & Lipid & ww & Lipid \\
\hline \multicolumn{7}{|l|}{ Site 1} \\
\hline $50: 1$ & 20 & 29 & 30 & 45 & 27 & 14 \\
\hline $27: 1$ & 12 & 23 & 16 & 45 & 41 & 25 \\
\hline $140 \mathrm{ml} / \mathrm{g}$ & 21 & 21 & 5 & 35 & 22 & 10 \\
\hline \multicolumn{7}{|l|}{ Site 2} \\
\hline $50: 1$ & 22 & 46 & 15 & 22 & 28 & 16 \\
\hline $27: 1$ & 24 & 48 & 24 & 30 & 31 & 21 \\
\hline $140 \mathrm{ml} / \mathrm{g}$ & 28 & 91 & 25 & 44 & 9 & 9 \\
\hline \multicolumn{7}{|c|}{ Within-test variability ${ }^{\mathrm{a}}$} \\
\hline & $10-25$ & $21-59$ & $7-28$ & $19-30$ & $4-23$ & $10-22$ \\
\hline
\end{tabular}

Loading densities $=50: 1$ and 27:1 TOC:organism dw and $140 \mathrm{ml}$ sediment/g ww tissue. Data are from three repeated tests

a 2007/08 method evaluation with 27:1 density, 3 replicates/test, and 2 to 6 sediments 

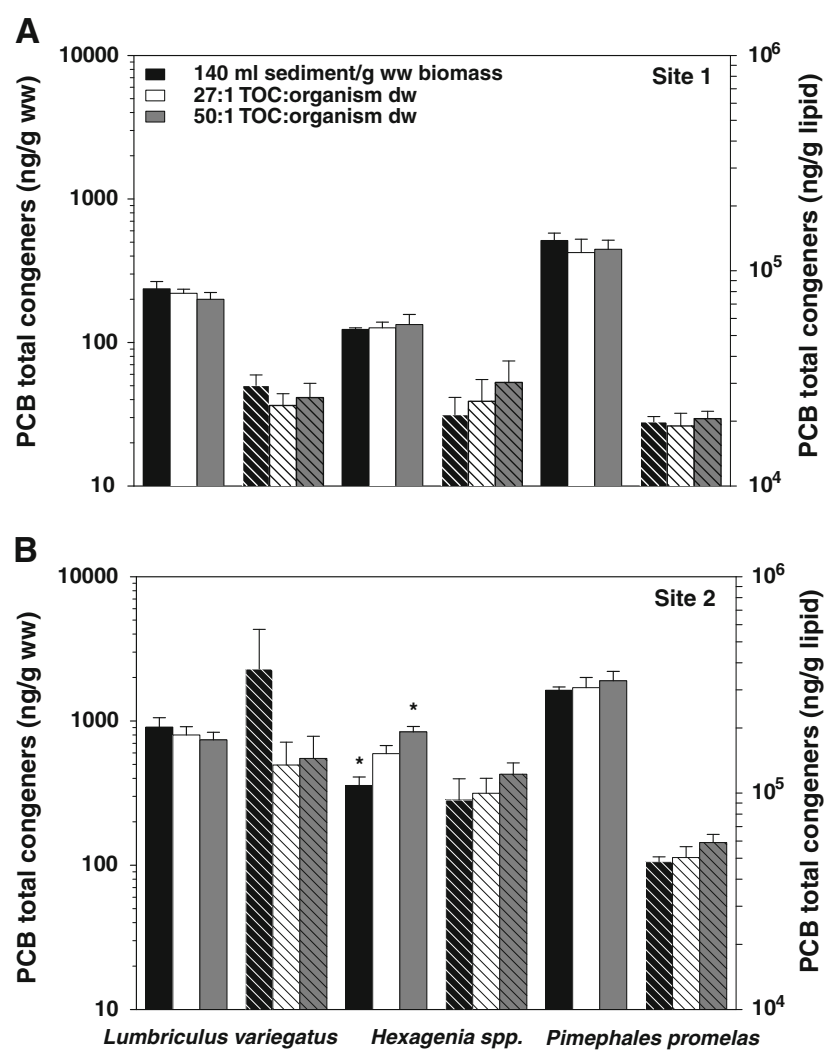

Fig. 3 Effect of organism density on the bioaccumulation of PCBs from sediment in L. variegatus, Hexagenia spp., and $P$. promelas. Solid bars represent tissue concentrations on a ww basis and hatched bars on a lipid basis. Data are reported as means and SEs generated from repeated tests $(n=3)$. * Statistically significant results (ANOVA $P \leq 0.05$ )

Each species accumulated PCBs from the sediment collected at site 1 . On a ww basis, $P$. promelas accumulated higher concentrations of PCBs than $L$. variegatus and Hexagenia spp. (Fig. 3a). However, when tissue concentrations were normalized for lipid content, the concentrations in minnows were approximately 7 to $32 \%$ lower than in the invertebrates. The density of organisms did not significantly affect the bioaccumulation of total PCBs in any of the species exposed to site 1 sediment. Comparison of PCB homologues also showed no effect of organism density (data not shown).

All three organisms accumulated PCBs from sediment collected at site 2 up to concentrations that were approximately four times higher than those for site 1 . Although the measured concentration of total PCBs in this sediment was lower than for site 1 , when expressed on the basis of organic carbon, PCB concentrations were almost three times higher (Table S1). In sediment from site 2, greater differences in PCB accumulation between the three species was observed, again with $P$. promelas accumulating lower concentrations on a lipid basis (Fig. 3b). For L. variegatus, there again was no significant difference in bioaccumulation between loading densities on a ww or lipid basis. However, extremely high concentrations of PCBs were observed in the standard volume treatment (140 ml sediment/g ww biomass) for the lipid-normalized data due to the differences in lipid content between the density treatments in test 3 ( 0.2 vs. $0.6 \%$; discussed previously). This resulted in high variability in lipid-normalized data between tests for this density treatment $(\mathrm{CV}=91 \%)$. In Hexagenia nymphs exposed to sediment from site 2, PCB accumulation increased with increasing TOC/decreasing organism density (Fig. 3b). There was a significant difference in tissue concentrations between the highest and lowest loading density based on ww; however, when the data were corrected for lipid content, this difference was not significant. A slight increase in PCB accumulation was also observed for $P$. promelas across the three treatments, but this trend was not significant. Comparison of PCB homologues resulted in similar observations to total PCBs for all three species. Significant differences were observed on a ww basis for Hexagenia spp. (tetra-, penta- and hepta-homologues only), but not when tissue concentrations were normalized for lipid (data not shown).

\section{Discussion}

\section{Effect of Organism Density}

In the present study, although there was no significant difference in bioaccumulation between loading densities for $L$. variegatus, higher concentrations were sometimes observed at the highest organism density (lowest ratio of TOC:organism dw). This was similar to what was observed by Kukkonen and Landrum (1994) in a study that assessed the toxicity and kinetics of pyrene in spiked sediment with L. variegatus, which also included different organism densities. These investigators compared 7-day tissue concentrations at 5:1, 10:1, and 50:1 ratios of TOC:organism $\mathrm{dw}$ and 14-day concentrations at 10:1, 50:1, and 100:1 ratios of TOC:organism dw. Compared with the present study, they observed a statistically significant difference in tissue residues between densities of organisms. This is likely due to the much greater relative difference between loading densities in their study $(2 \times$ to $10 \times)$. Kukkonen and Landrum (1994) suggested that the porosity of the sediment may be increased at the higher organism density due to burrowing activity, thereby increasing the porewater volume and accumulation from this route of exposure. In addition, this may have altered the sediment-porewater equilibrium, causing more contaminant to enter the porewater. Alternatively, they suggested that the depletion of the best possible fraction of food (i.e., highest-quality food) 
at high organism densities would cause an increase in feeding rates of the remaining food source and that increased feeding would result in higher body burdens. They also observed that the average and total biomass of $L$. variegatus decreased in all treatments, including the control. As in the present study, they did not observe a relationship between growth and density of oligochaetes.

Both Hexagenia spp. and $P$. promelas can cause significant resuspension of sediments due to their behaviour, but little of this was visually observed with $L$. variegatus in the present study. In our study, PCBs in overlying water were detected at trace amounts, or were lower than detection limits, with no apparent trends across treatments, suggesting that movement of PCBs to the overlying water was not affected by the density of the worms (Table S3). Lotufo et al. (2000) assessed how exposure source, worm density, and sex affected the toxicity and bioaccumulation of DDT in the marine polychaete $N$. arenaceodentata. The polychaete worms were exposed individually or in groups of five to $50 \mathrm{ml}$ sediment spiked with a range of concentrations of DDT. Worms that were exposed individually accumulated relatively more DDT than those at the higher organism density. Compared with Kukkonen and Landrum (1994), these investigators suggested that an increase in bioturbation under higher worm density may have increased exchange between overlying water and porewater, thus decreasing exposure to porewater DDT.

In the present study, a significant difference in bioaccumulation was only observed between the highest and lowest densities in Hexagenia spp. exposed to sediment from site 2 and only when tissue concentrations were expressed on the basis of ww. This difference in accumulation of PCBs may be influenced by the increased competition for low resources of TOC in the standard volume treatment, which resulted in decreased survival in two of the three tests and minimal growth in the case where survival was not adversely impacted. Growth of Hexagenia spp. increased with the amount of TOC provided, and growth-dilution of contaminants may have occurred. However, differences in growth between organism densities were not significant for either of the PCB-contaminated sediments. In two of the three experiments in which Hexagenia spp. were exposed to sediment from site 2, the concentration of PCBs in the overlying water was approximately 1.8 times higher in the standard volume treatment than the other two treatments (although measured at trace amounts; Table S3). In part, this supports the explanation for differential accumulation offered by Lotufo et al. (2000), in that higher organism density may have caused increased bioturbation and movement of contaminant from the sediment and/or porewater into the overlying water. However, concentrations of PCBs in the overlying water of the 50:1 and 27:1 treatments in the present study were not different from each other (Table S3).

Lipid-normalized concentrations of PCB were $\leq 60 \%$ lower in Pimephales promelas compared with the other tests species, and bioaccumulation was not affected by the proportion of sediment TOC, both of which may be expected from an organism that resides in the water column. It is possible that surface area, rather than volume, of sediment may affect bioaccumulation in this species by influencing partitioning of the contaminant from sediment to overlying water and the amount of sediment available for the fish to interact with. It should be noted that the 27:1 and 50:1 treatments were split between test vessels for $P$. promelas due to the requirement for large volumes of sediment and overlying water. Although this resulted in fewer numbers of fish per vessel in the split treatments, it had no effect on bioaccumulation in this species.

\section{Standardizing to Sediment TOC}

It has been suggested that density of organisms in bioaccumulation tests should be standardized relative to sediment organic carbon (Kukkonen and Landrum 1994). Based on our observations with the invertebrate species in the present study, we agree that density should be standardized relative to TOC instead of a fixed volume of sediment. Survival of Hexagenia spp. was lower than acceptable levels and more variable in the standard volume treatment when the concentration of TOC was low, including the control sediment. This impact on organism health has the potential to influence bioaccumulation and may have been a confounding factor that contributed to the significant difference in bioaccumulation between the highest and lowest density (=lowest and highest ratios of TOC:organism dw) treatments. Bioaccumulation by L. variegatus in sediment from site 2 was also extremely variable in the standard volume treatment. Since organic carbon is a food source for benthic organisms and varies in both quantity and composition between sediments, providing a sufficient amount in a long-term test is a means of meeting the nutritional needs of the organism while assessing bioaccumulation through this particular route of exposure.

\section{Selection of a Loading Density}

The selection of a loading density of organisms for a standard bioaccumulation method should take into account the conclusions of the present study or those of Kukkonen and Landrum (1994), but it should also consider the practicality of the method. Therefore, for the following reasons we suggest that an approximately 27:1 ratio of TOC:organism $\mathrm{dw}$ is sufficient as a standard loading 
density for the OMOE bioaccumulation method. When provided with a 50:1 ratio of TOC:organism dw, which is suggested in the ASTM (2000) and USEPA (2000) methods, $L$. variegatus did not grow or bioaccumulate higher concentrations of PCBs than at the 27:1 density. However, the greater volume of sediment required to meet the former ratio resulted in a much greater effort to recover organisms. There was also no significant difference in tissue concentrations of PCBs between the 50:1 and 27:1 treatments for Hexagenia spp. or P. promelas. Coefficients of variation for tissue concentrations (ww or lipid-normalized) of organisms in the 27:1 treatment were not consistently higher or lower than those for the 50:1 treatment, indicating that biological variability is likely greater than any variability associated with these two treatments. Furthermore, in the 27:1 treatment, survival of Hexagenia spp. was not affected in any of the sediments and growth was not excessive, which is known to be a potentially important confounding factor (i.e., growth dilution of contaminants or emergence of the adults) in bioaccumulation assessments.

\section{Summary and Conclusion}

Density of organisms did not significantly affect growth, lipid content, or bioaccumulation in $L$. variegatus, despite organisms in the high-density treatments having slightly higher concentrations of PCBs. Survival of Hexagenia spp. was not significantly affected by organism density, but was more variable and sometimes impacted when the amount of TOC was low $(\leq 16: 1)$. Growth of nymphs was highest at the low organism density (high TOC), but a significant difference between treatments was only observed in the control sediment. In cases where the ratio of TOC to organism dw was low and survival of nymphs was not impacted, the lipid content was relatively low compared with the other density treatments due to competition for limited TOC resources. Density of organisms significantly affected bioaccumulation in nymphs only in sediment from site 2 and only with tissue concentrations expressed on a ww basis. Density did not significantly affect survival, growth, lipid content, or bioaccumulation in P. promelas.

Standardizing the loading density of organisms relative to sediment organic carbon is important to achieve good survival and growth of organisms that burrow into and ingest sediment, particularly when a method may be applied to a broad range of sediments (that vary in their physical characteristics). These measures of organism performance in a test can indicate whether the health of organisms has been compromised, which may influence exposure and therefore bioaccumulation results. A 27:1 ratio of TOC:organism dw did not impact bioaccumulation relative to the 50:1 ratio recommended in existing bioaccumulation methods, and it is therefore recommended as an appropriate ratio for sediment bioaccumulation assessments in general.

The present study only examined the effect of organism density (standardized to sediment volume or TOC and different ratios of TOC:organism dw) on bioaccumulation with two sediments and PCBs as the contaminant of concern. However, we think that the results of this study are sufficient to demonstrate the importance of standardizing to sediment organic carbon and provide a basis for the selection of a loading density to use in bioaccumulationmethod development. This will facilitate a more consistent approach to the assessment of bioaccumulation from sediment and for the pursuit of other research hypotheses. Future work includes definitive testing of field-collected sediments ( $n=9$ to 12 ) to assess the effectiveness of the three species for accumulating a variety of sedimentassociated contaminants (i.e., PCBs and dioxin-like PCBs, dioxins and furans, DDT and metabolites, and mercury).

Acknowledgments We thank S. Petro of the OMOE's Sport Fish and Biomonitoring Unit for the collection of sediment. Thanks also to the staff in the Aquatic Toxicology Unit for assistance in culturing test organisms and to the other sections of the OMOE Laboratory Services Branch for analytic support. This work was supported by the OMOE Best in Science Program (Project No. 6703).

\section{References}

American Society for Testing and Materials (2000) Standard guide for determination of the bioaccumulation of sediment-associated contaminants by benthic invertebrates (E1688-00a) In: Annual book of ASTM standards, vol 1105. ATSM, Philadelphia, PA, p 53

Bedard D, Hayton A, Persaud D (1992) Laboratory sediment biological testing protocol. Ontario Ministry of the Environment, Queen's Printer for Ontario, Ontorio, p 26

Chapman PM, Anderson J (2005) A decision-making framework for sediment contamination. Integr Environ Assess Manag $1: 163-173$

Environment Canada (1997a) Biological test method: test for survival and growth in sediment using the freshwater amphipod Hyalella azteca (EPS 1/RM/33). In: Environmental Protection Series, Ottawa, Ontario, Canada, p 117

Environment Canada (1997b) Biological test method: test for survival and growth in sediment using the larvae of freshwater midges (Chironomus tentans or Chironomus riparius) (EPS 1/RM/32). In: Environmental Protection Series, Ottawa, Ontario, Canada, p 125

Grapentine L, Anderson J, Boyd D, Burton GA, DeBarros C, Johnson $G$ et al (2002) A decision making framework for sediment assessment developed for the Great Lakes. Hum Ecol Risk Assess 8:1641-1655

Hanes EC, Ciborowski JJH, Corkum LD (1990) Standardized rearing materials and procedures for Hexagenia, a benthic bioassay organism: comparison of sediment types. In: Ontario ministry of the environment technology transfer conference on environmental research, vol 1, Toronto, Ontario, Canada, pp 374-382 
Harkey GA, Van Hoof PL, Landrum PF (1995) Bioavailability of polycyclic aromatic hydrocarbons from a historically contaminated sediment core. Environ Toxicol Chem 14:1551-1560

Kukkonen JVK, Landrum PF (1994) Toxicokinetics and toxicity of sediment-associated pyrene to Lumbriculus variegatus (Oligochaeta). Environ Toxicol Chem 13:1457-1468

Kukkonen J, Landrum PF (1995) Effects of sediment-bound polydimethyl siloxane on the bioavailability and distribution of benzo[a]pyrene in lake sediment to Lumbriculus variegatus. Environ Toxicol Chem 14:523-531

Leppänen MT (1995) The role of feeding behavior in bioaccumulation of organic chemicals in benthic organisms. Annales Zoologici Fennici 32:247-255

Leppänen MT, Kukkonen JVK (1998) Factors affecting feeding rate, reproduction and growth of an oligochaete Lumbriculus variegatus (Müller). Hydrobiologia 377:183-194

Leppänen MT, Kukkonen JVK (2004) Toxicokinetics of sedimentassociated polybrominated diphenylethers (flame retardants) in benthic invertebrates (Lumbriculus variegatus, Oligochaeta). Environ Toxicol Chem 23:166-172

Lotufo GR, Farrar JD, Bridges TS (2000) Effects of exposure source, worm density, and sex on DDT bioaccumulation and toxicity in the marine polychaete Neanthes arenaceodentata. Environ Toxicol Chem 19:472-484

Lyytikäinen M, Pehkonen S, Akkanen J, Leppänen MT, Kukkonen JVK (2007) Bioaccumulation and biotransformation of polycyclic aromatic hydrocarbons during sediment tests with oligochaetes (Lumbriculus variegatus). Environ Toxicol Chem 26:2660-2666

Ontario Ministry of the Environment (2007) The determination of polychlorinated biphenyl congeners (PCBs) in fish, clams and mussels by gas liquid chromatography-electron capture detection (PCBC-E3411). Laboratory Services Branch, Toronto, Ontario, Canada
Ontario Ministry of the Environment (2008a) The determination of total carbon in soil and sediments by thermal oxidation and infrared detection (CARBONTC-E3142). Laboratory Services Branch, Toronto, Ontario, Canada

Ontario Ministry of the Environment (2008b) The determination of total carbonate-carbon in soil and sediments by coulometry (CARBONAT-E3012). Laboratory Services Branch, Toronto, Ontario, Canada

Ontario Ministry of the Environment (2008c) The determination of particle size distribution on sediments, particulate matter and liquids by coulter model LS230 particle size analyzer (LLPARTE3328). Laboratory Services Branch, Toronto, Ontario, Canada

Ontario Ministry of the Environment (2008d) The determination of polychlorinated biphenyl congeners (PCBs) in soil, sediment and vegetation by gas liquid chromatography-electron capture detection (PCBC-E3412). Laboratory Services Branch, Toronto, Ontario, Canada

Ontario Ministry of the Environment (2008e) Hexagenia spp. test for survival and growth in sediment (HXMOE-E3444). Laboratory Services Branch, Toronto, Ontario, Canada

United States Environmental Protection Agency (1987) Guidelines for the culture of fathead minnows, Pimephales promelas, for use in toxicity tests. EPA 600/3/87/001, Duluth, MN, p 42

United States Environmental Protection Agency (2000) Methods for measuring the toxicity and bioaccumulation of sediment-associated contaminants with freshwater invertebrates, 2nd edn. EPA 600/R-99/064. Duluth, MN, p 212

Van Geest JL, Poirier DG, Solomon KR, Sibley PK (2010) Measuring bioaccumulation of contaminants from field-collected sediment in freshwater organisms: A critical review of laboratory methods. Environ Toxicol Chem, in press.

You J, Landrum PF, Trimble TA, Lydy MJ (2007) Availability of polychlorinated biphenyls in field-contaminated sediment. Environ Toxicol Chem 26:1940-1948 